Cahiers $d u$ MONDE RUSSE

\section{Cahiers du monde russe}

Russie - Empire russe - Union soviétique et États indépendants

$49 / 4 \mid 2008$

Destins individuels et terreur. Jeunesse dans la société post-stalinienne

\title{
Rudolf G. Pikhoia, URSS : Histoire du pouvoir
}

\section{5-1981}

\section{Alain Blum}

\section{OpenEdition}

\section{Journals}

Édition électronique

URL : https://journals.openedition.org/monderusse/6944

DOI : 10.4000/monderusse.6944

ISSN : $1777-5388$

Éditeur

Éditions de l'EHESS

\section{Édition imprimée}

Date de publication : 28 décembre 2008

Pagination : 758-760

ISBN : 978-2-7132-2197-2

ISSN : $1252-6576$

Référence électronique

Alain Blum, «Rudolf G. Pikhoia, URSS : Histoire du pouvoir 1945-1981 », Cahiers du monde russe [En ligne], 49/4 | 2008, mis en ligne le 23 décembre 2009, consulté le 02 septembre 2022. URL : http:// journals.openedition.org/monderusse/6944; DOI : https://doi.org/10.4000/monderusse.6944

Ce document a été généré automatiquement le 2 septembre 2022

Tous droits réservés 


\title{
Rudolf G. Pikhoia, URSS : Histoire du pouvoir 1945-1981
}

\author{
Alain Blum
}

\section{RÉFÉRENCE}

Rudolf G. PIKHOIA, URSS : Histoire du pouvoir 1945-1981. Vol. 1 : Quarante ans

d'après-guerre. Vol. 2 : Le retour de l'aigle bicéphale. Traduit du russe par Benoît

Gascon. Longueil, Québec : Les éditions Kéruss, 2007-2008, 750 + 514 p.

1 L'ouvrage de Rudolf Pikhoia paru en 1998 a constitué alors un moment important de l'écriture d'une nouvelle histoire de l'URSS. Sa traduction en français justifie cette note de lecture dix ans après la parution de l'ouvrage original, deux ans seulement après la parution d'une nouvelle édition augmentée.

2 Pikhoia fut, rappelons-le, directeur des archives nationales de Russie durant 7 ans, entre 1990 et 1996. Il fut à ce titre un double témoin : d'une part celui de la redécouverte et de la réécriture d'une histoire fondée sur l'ouverture sans précédent d'archives jusqu'alors inaccessibles - et celui qui eut un accès direct à toutes ces archives. L'un des grands intérêts de l'ouvrage consiste en la mise à disposition de documents jusqu'alors inconnus. Mais Pikhoia fut d'autre part le témoin direct de la carrière politique de Boris El'cin, bien avant l'accession de celui-ci au pouvoir (ne sont-ils pas tous deux de Sverdlovsk, désormais Iekaterinbourg ?). La dernière partie de l'ouvrage s'ancre ainsi sur une expérience directe du pouvoir, une connaissance intime du gouvernement $\mathrm{El}^{\prime}$ cin.

On sait que l'un des principaux intérêts de l'ouvrage de Pikhoia a consisté en une attention toute particulière aux agencements $d u$ pouvoir, aux arrangements entredirigeants, aux luttes au sommet de l'État. Ainsi l'auteur est-il passionnant lorsqu'il dépeint les tensions et confrontations autour de Stalin après la Seconde Guerre mondiale, démontant les mécanismes d'accusation et d'arrestation qui s'ensuivirent. Il est tout aussi passionnant lorsqu'il évoque la lutte contre Malenkov et Berija avant leur chute, la préparation du XXe Congrès et les «secrets du Rapport secret ", ou encore 
lorsqu'il examine les causes de la destitution de Hruščev. Toutes ces analyses sont fondées sur des documents alors inédits, des verbatim de réunions au sommet ou autres formes de rapports. Il est vrai qu'un certain nombre de ces documents ont depuis été publiés.

Le second tome s'étend de 1982 à la fin de l'URSS. Bien qu'encore partiellement fondé sur des archives, il intègre l'expérience personnelle de Pikhoia. Le fil conducteur en est la lente destruction d'un pouvoir soviétique longtemps malade avant que d'en mourir. L'histoire est scandée par une série d'affaires (celle de la mafia ouzbek, du Boeing sudcoréen abattu au-dessus de l'île de Sakhaline le $1^{\text {er }}$ septembre 1983, etc). Pikhoia étudie chaque fois avec attention les discussions entre dirigeants, exposant avec précision les mécanismes du pouvoir. Vient ensuite toute la période Gorbačev, objet central du volume. Il s'agit d'une présentation détaillée des relations entre dirigeants, mêlant souvenirs personnels, documents et nombreux mémoires d'acteurs de cette époque. Particulièrement riche est la période qui précède la déclaration de souveraineté de la Russie (le 12 juin 1990) jusqu'aux élections du Président de la Russie (le 12 juin 1991). Ce volume tend surtout à présenter une histoire qui s'achemine vers une fin inéluctable, toutes les tentatives de sauvetage ne pouvant qu'échouer.

Bien que l'ouvrage ait constitué en son temps un apportconsidérable, comment ne pas souligner qu'il mériterait aujourd'hui d'être enrichi des nombreux travaux publiés depuis? De ce fait, cette traduction arrive sans doute un peu tard. On regrettera aussi que les relations avec les autres acteurs internationaux du pouvoir soviétique - les dirigeants de l'Europe de l'Est - ne soient guère traitées. On pense plus généralement à la place de l'Europe de l'Est dans la puissance soviétique d'après-guerre, en particulier à son affaiblissement suivi de son anéantissement. Qu'il s'agisse de 1956, 1968 ou 1981, si les discussions au Politbjuro sont bien analysées, les acteurs hongrois, tchécoslovaques ou polonais ne sont guère présents et cette dimension est manifestement sous-évaluée pour comprendre le processus étudié.

Enfin, on aurait surtout préféré avoir accès à la nouvelle édition remaniée du livre, Moskva, Kreml' i vlast' [Moscou, le Kremlin et le pouvoir],parue en2007. Elle offre quelques ajouts importants et est enrichie d'une partie portant sur les années Putin, qui n'a cependant pas la qualité d'analyse de la période précédente.

7 Reste à évoquer la traduction... pour en souligner la médiocrité! Le texte fourmille d'erreurs élémentaires (Stalin aurait par exemple été élève de l'école religieuse de « Goritski »! - nombreux étant les toponymes où le suffixe de l'adjectif est maintenu...). Traduction lourde, accessible uniquement au russisant qui retrouvera sans effort, derrière la phrase française, la syntaxe et le vocabulaire russe qui lui sont familiers : « Si on veut, il s'agissait d'une intervention à double sens, sinon plus »; "L'avion est disparu et ce qui lui est arrivé par la suite, nous ne le savons pas» (t. 2, p. 36) ou encore "Le même jour éclata la sensation politique planifiée par Lukianov» (t. 2, p. 381). On a souvent l'impression que le traducteur s'est tout bonnement contenté d'une traduction mot à mot. Il semble inadmissible de voir paraître une traduction qui rend ce livre important quasiment illisible et le dessert au lieu de lui donner la place qu'il mérite. Qu'un éditeur ait pu laisser passer un tel travail ne peut que surprendre.

Revenons donc, si faire se peut, à la version originale. 